\title{
A QUANTITATIVE IMPEDANCE PNEUMOGRAPH
}

\author{
GEORGE E. BERGEY \\ Aerospace Medical Research Department \\ U. S. Naval Air Development Center \\ Johnsville, Warminster, Pennsylvania
}

Summary An impedance pneumograph capable of quantitatively measuring respiratory volumes is described. Physically, the pneumograph is one of several $3 / 8 \times 5 / 8$ $x 7 / 8$ inches modules incorporated in a miniature biotelemetry system, with separate modules being utilized to process signals derived from a number of physiological parameters such as EEG and EKG in addition to respiration. Considerable experimentation was performed regarding optimization of the electrodes used in this impedance pneumograph as well as the frequency and amplitude of the excitation voltage applied between the electrodes. The result was a fairly simple and inexpensive device which uses a higher frequency $(300 \mathrm{KHz})$ excitation voltage than is normally used in impedance pneumography. The two electrodes, constructed of silver coated nylon for flexibility, are insulated from the subject by a layer of polyethylene film, thus forming a capacitive coupling of the electrode to the subject. This technique effectively eliminates changes in skin-to-electrode resistance, largely responsible for baseline drift encountered with previous impedance systems, so that this pneumograph responds only to variations in the actual impedance between the two electrodes. Empirically, a nearly perfect linear correlation was found to exist between the transthoracic impedance measured by this impedance pneumograph and pulmonary volume. The two insulated electrodes are pasteless and therefore easily applicable and non-irritating. They are held in position by an elastic, quick-donning, vest-like garment.

Introduction This report describes the efforts of the Physiology Division at the U. S. Naval Air Development Center toward the development of a device which has been used extensively to measure tidal volumes of human subjects .

Previous attempts have been made by a number of investigators to quantitatively correlate transthoracic impedance variations with pulmonary volume changes. The advantages of the impedance technique are obvious: no restraint is placed on the subject; the entire system can be made small and light in weight, worn for relatively long periods of time, and used for a variety of applications. 
The technique described in this report differs from other impedance pneumography systems in that the frequency of the alternating current applied to a pair of electrodes is considerably higher, $300 \mathrm{KHz}$, than that used by most experimenters. More importantly, the two electrodes are insulated from the subject's skin. This insulation of electrodes eliminates variation in the resistance between skin and electrode which bears little relevance to variation in pulmonary volume. Empirically, a close correlation was found to exist between the transthoracic impedance as measured by this pneumograph and tidal volume.

This impedance pneumograph was designed to be compatible with a telemetry system capable of measuring other physiological parameters such as electrocardiogram, electroencephalogram, temperature, and blood pressure. The electrodes developed for both EKG and respiration were pasteless and therefore easily applicable, non-irritating, and capable of being worn for extended periods of time. (See Figure 1).

Use of a microtransistor and miniaturized components enable compact construction of the impedance pneumograph for applications where space is critical. This particular unit, after encapsulation in epoxy, measured 3/8 x 5/8 x 7/8 inches. (See Figure 2).

Circuit Description Basically, the impedance pneumograph consists of a single transistor Colpitts oscillator purposely designed to have a relatively high output impedance of $2000 \mathrm{ohms}$ so that small changes in the load impedance will cause the amplitude of the excitation to vary considerably. At 300 kilohertz, the load impedance, using the electrodes yet to be described, is approximately $6800 \mathrm{ohms}$. Respiration causes this impedance to vary about $20 \mathrm{ohms}$ per liter, depending, of course, to some extent, on the subjects. (See Figure 3). The varying-amplitude excitation signal or carrier is then demodulated using a half-wave rectifier filter, thus producing a direct current whose voltage is proportional to the oscillator load; that is, the transthoracic impedance. As can be seen from this calibration curve, the D.C. output of pneumograph varies linearly with pulmonary volume. The slope of this calibration curve varies somewhat with the physical habitus of the subject and his body position; that is, the pneumograph's sensitivity is slightly different if the subject is lying down than if he is, say, standing or sitting. Hence, for quantitative results, it is necessary to calibrate the pneumograph for each subject on whom it is to be used. Although the slope of the calibration curve varies as described, a linear relationship between the pneumograph output and pulmonary volume always exists. This D.C. output can then be used to drive a high impedance recorder directly or to drive a voltage-controlled subcarrier oscillator for use in an FM-FM telemetry system. Telemetering the signal appears to be the most advantageous method in that artifacts due to changes in the subject's position relative to ground are minimized. If the signal is coupled to a recorder directly, movement artifact results when one foot is raised off the floor, or when the subject changes his proximity to grounded equipment. 
Considerable experimentation was done concerning the optimum frequency at which to operate the pneumograph oscillator. (See Figure 4). Previous attempts at impedance pneumography utilized frequencies in the 25 to $100 \mathrm{KHz}$ range. In spite of the findings of previous investigators, the sensitivity of this pneumograph was found to increase as the oscillator frequency was increased to about $360 \mathrm{KHz}$ as shown in this chart. Higher frequencies were tried with little success, possibly because of skin effect or some other phenomenon which altered the pathway of the RF radiated between the electrodes.

Figure 5 shows a recording of pulmonary volume as recorded simultaneously by this impedance pneumograph (top trace) and a standard recording wedge spirometer (bottom trace). The subject purposely varied his respiration so as to include a wide range of respiratory volumes and rates.

Electrodes Previous attempts to measure pulmonary volumes with impedance devices have utilized electrodes placed in direct contact with the subject's skin to measure transthoracic impedance. To eliminate the variation in electrode-skin impedance, the electrodes of this system were insulated from the subject's skin with a thin polyethylene film, thus forming a capacitive coupling of the electrode to the subject. Since the skintoelectrode resistance is now constant, the oscillator load varies only with the impedance between electrodes and proportionally with the volume of air in the lungs. Also, baseline drift, normally due to skin-to-electrode resistance changes, is eliminated.

The electrodes for the impedance pneumograph were constructed of silver coated nylon. Each electrode was constructed of two 4-3/4 x 6-3/8 inches rectangles fastened together along all four edges with a strip of cotton edging $1 / 2$ inch wide. Electrical connection was made to the metallized cloth by soldering lengths of 24 gauge stranded, plastic insulated wire to a size 15 snap fastener inserted through one corner of the electrodes approximately $1 / 2$ inch from 2 edges. These electrodes were then sealed in small polyethylene sandwich-wrapping bags called "Baggies" to insulate the electrodes from the subject.

The electrodes were placed transthoracically on the midaxillary line with the top edge of each electrode placed at the level of the lower edge of the areolae. Smaller electrodes were more subject to artifact resulting from arm movement and pressure on the electrodes. Larger electrodes produced a nonlinear output at extremes of the respiratory cycle, presumably because of the interposition of various internal organs; e.g., the liver.

Other systems have been described which use common electrodes for monitoring EKG and respiration. Since insulated electrodes could not be used for the relatively low frequency voltages of EKG, the telemetry system of which this pneumograph is a part utilizes separate electrodes for measuring respiration and EKG. It was felt that this method would not detract from the advantages of the system since the separate electrodes 
can be placed on the subject as a unit with the smaller EKG electrode placed in contact with the subject's chest.

Vests A unique feature of the overall telemetry system involves the use of a vest (see figure 6) to hold the pasteless EKG and respiration electrodes in place on the subject. Two pockets in the front of the vest hold the packages containing the transmitter, amplifiers, impedance pneumograph, and VCO's. A number of styles of these elastic vests have been designed and fabricated in our laboratory, the most recent model of which is shown in figure 6 . The larger electrodes on the bottom of the figure are for the pneumograph. The smaller, white bordered squares are EKG electrodes. The two pockets contain the biotelemetry system. To the left of the vest is one of several Lycra brassierre expanders which can be inserted with hook fasteners to adjust the size of the vest to fit a wide variety of subjects. The vest is constructed of Lycra and stretch denim resulting in a very compliant garment which imposes little physiological or psychological restriction to normal breathing. Figure 7 shows a subject wearing the vest which holds in place the pasteless electrodes for the pneumograp . No lengthy preparation of the subject is required; he need only don this garment to have his respiration telemetered to a nearby receiving site.

Discussion The exact nature and cause of the variations in transthoracic impedance measured by this device have not yet been ascertained. Other investigators have reported that the primary component of the impedance which varies with respiration is the resistance while the reactive component remains essentially constant. Other speculations implicate variations of blood volume in the chest, air in the lungs, lung tissue density, or electrode coupling as being responsible for the impedance changes noted.

Previously, our efforts had been directed primarily toward establishing the empiric correlations I have described. This correlation having been established, and a simple, reliable device developed for monitoring respiration, we now plan to undertake a more thorough investigation of precisely what physical parameter is responsible for the results we have noted. We have begun such experimentation, but to date are not prepared to draw any definite conclusions.

To summarize, I have described an impedance pneumograph capable of measuring respiratory volumes quantitatively. The principal feature of this system involves the use of pasteless electrodes which are insulated from the subject by a layer of polyethylene, thus forming a capacitive coupling of the electrodes to the subject and eliminating the problems associated with skin-to-electrode resistance variations. Empirically, a high degree of linearity was found to exist between the transthoracic impedance measured by this device and pulmonary volume. 


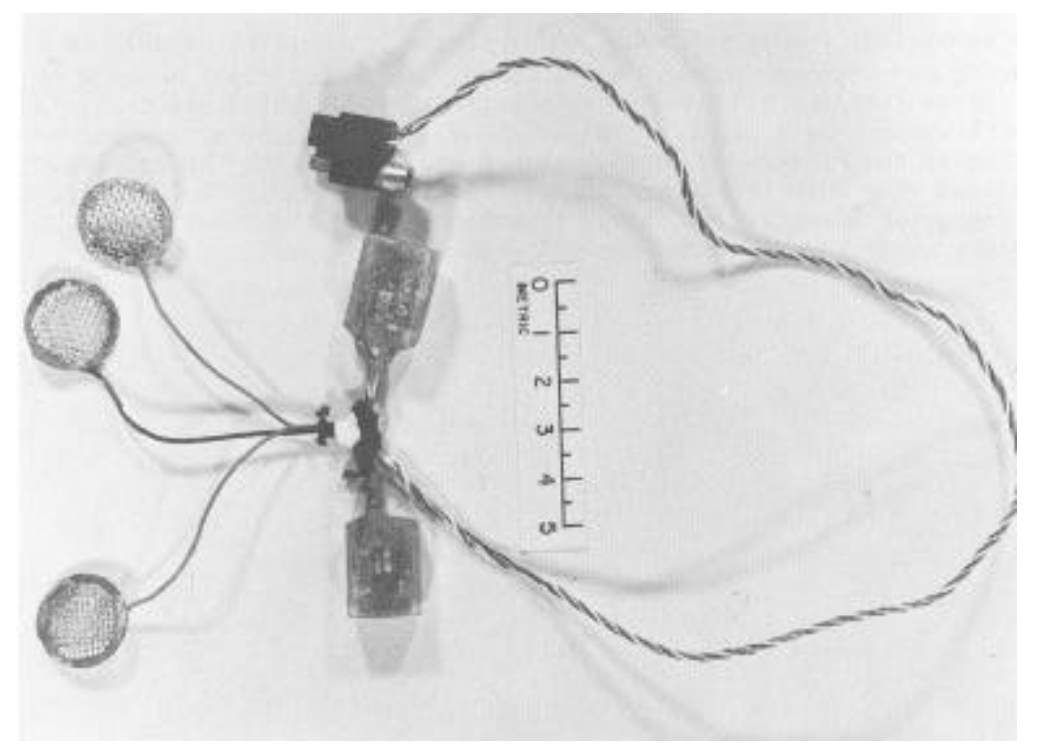

Fig. 1 - Impedance Pneumograph Module

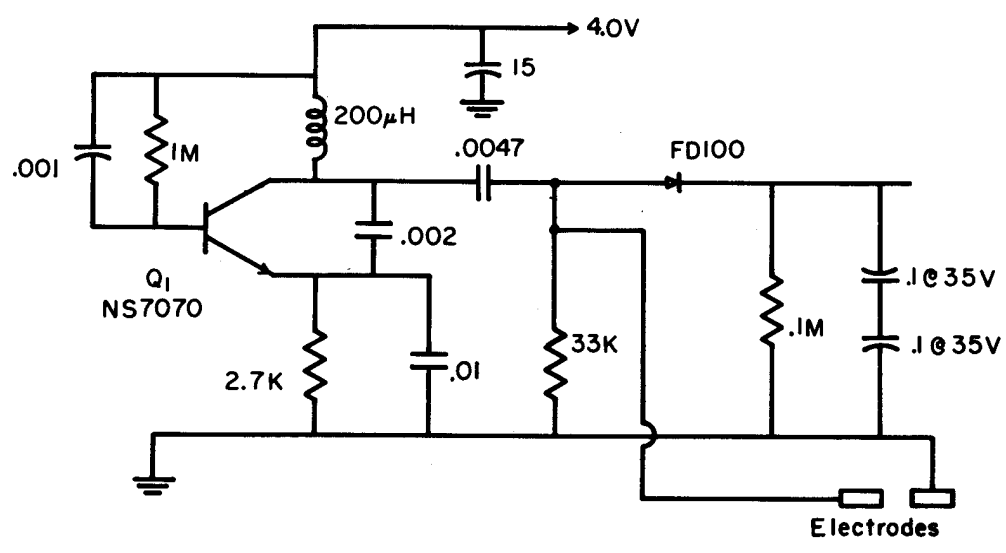

Fig. 2 - Schematic Diagram of Impedance Pneumograph

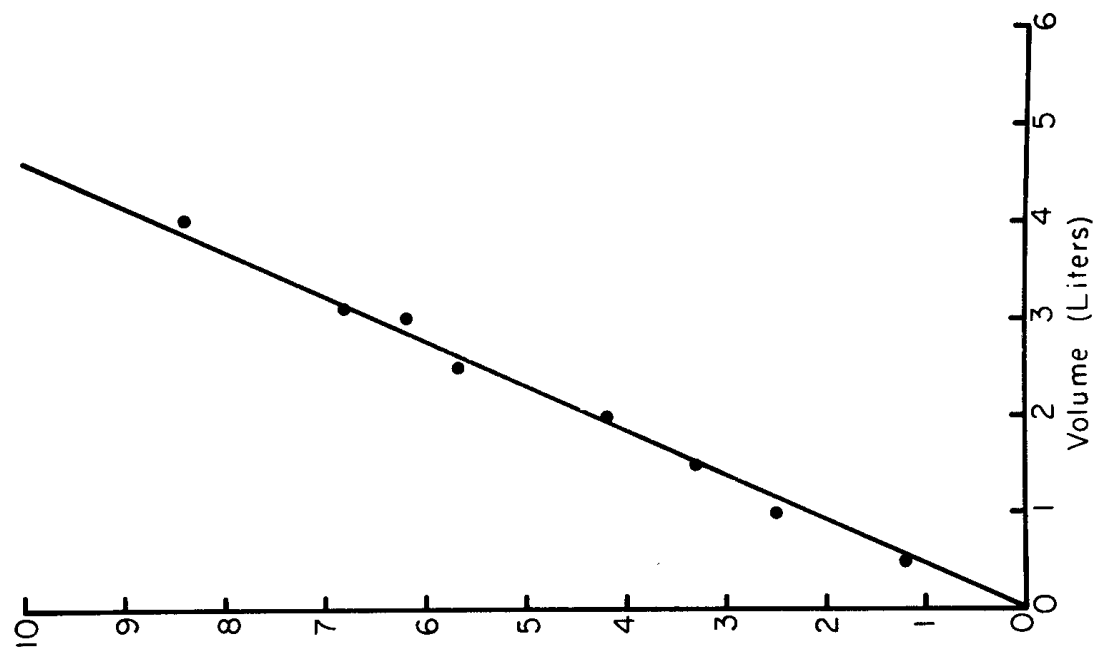

Fig. 3 - Calibration Curve 


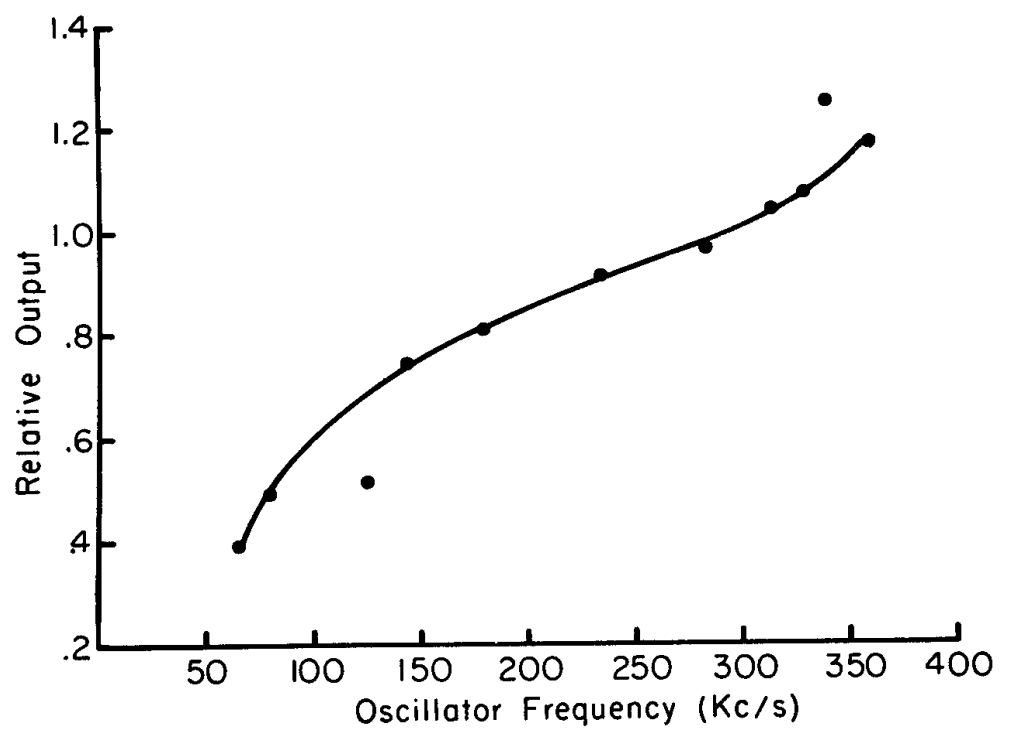

Fig. 4 - Attenuation vs. Oscillator Frequency

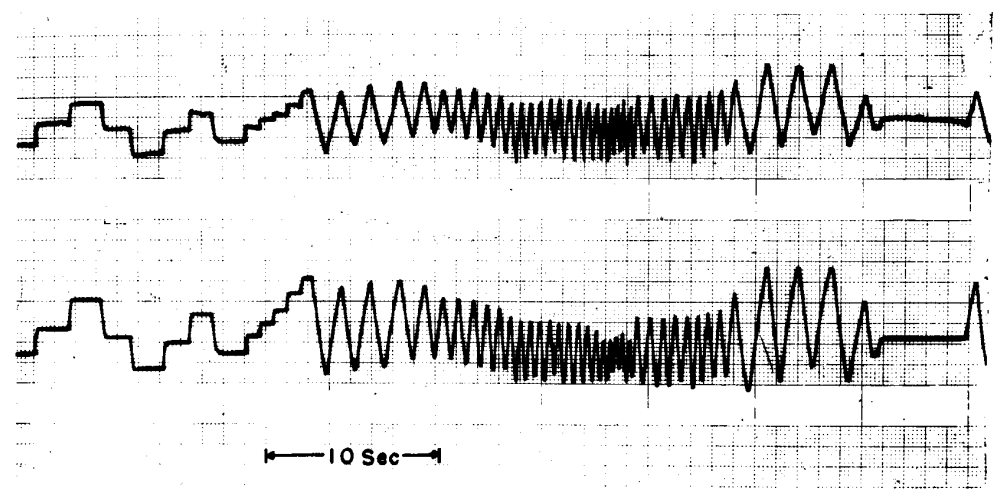

Fig. 5 - Spirometer and Pneumograph Tracings

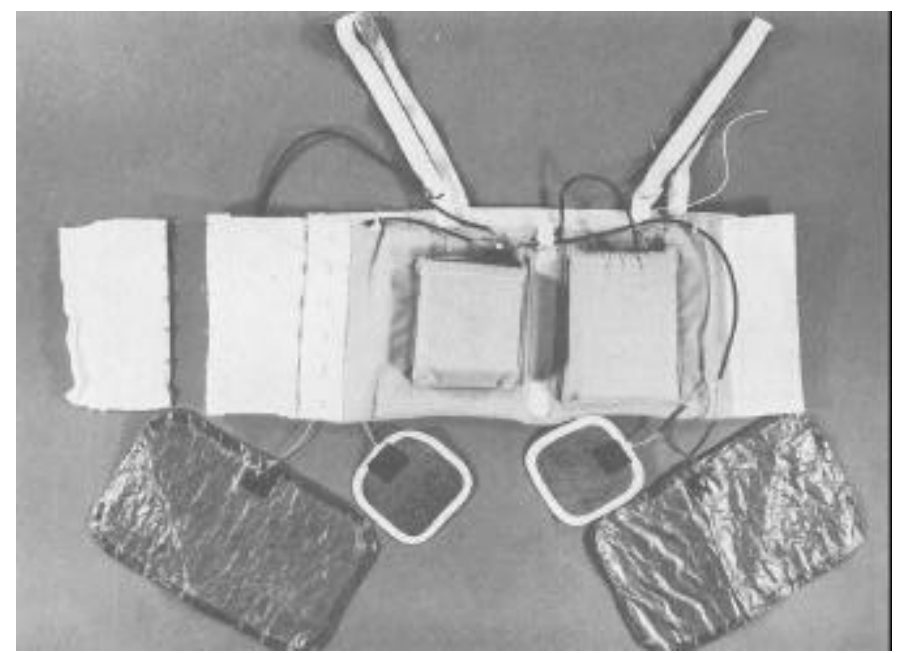

Fig. 6 - Vest 


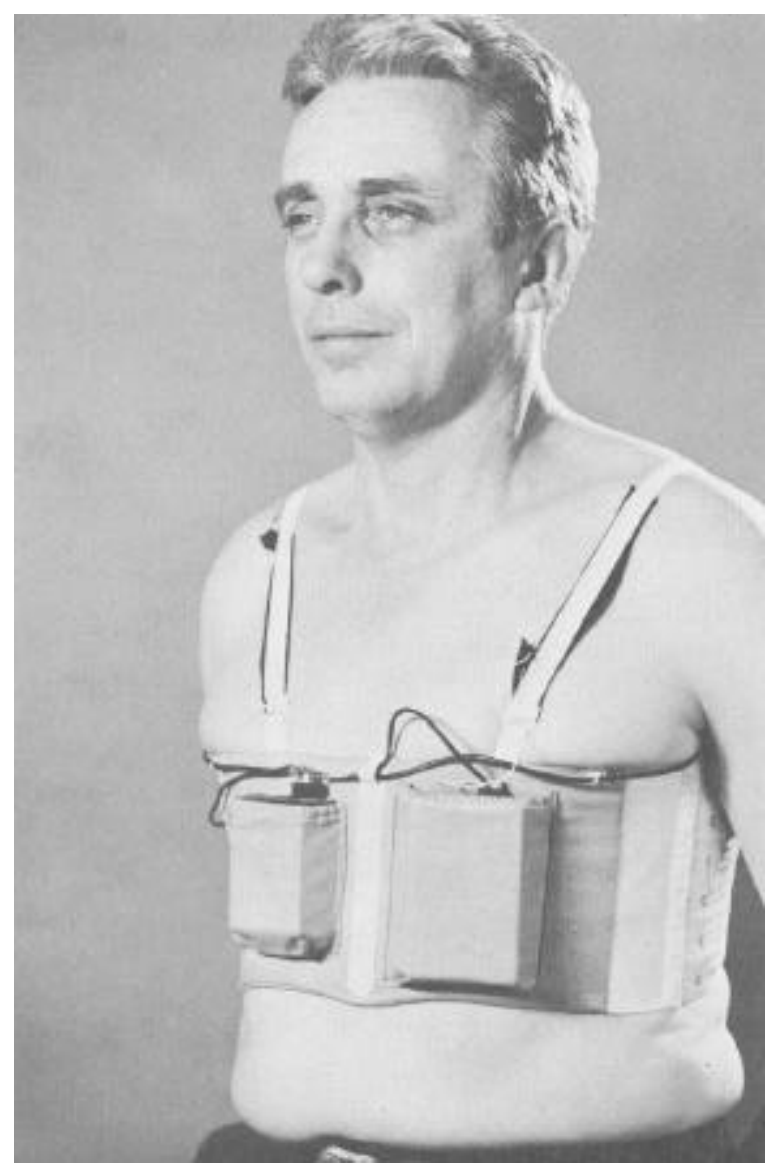

Fig. 7 - Vest on Subject 